\title{
Serotonin and serotonin transporter levels in autistic children
}

\author{
Haidar A. Abdulamir, MSc, PhD, Omar F. Abdul-Rasheed, MSc, PhD, Emad A. Abdulghani, MBChB, FIBMS.
}

\section{ABSTRACT}

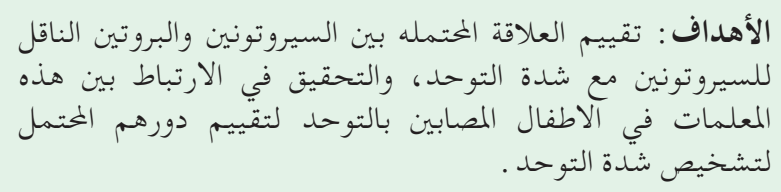

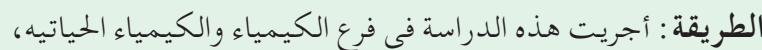

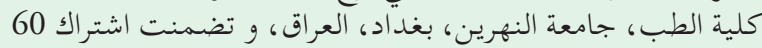

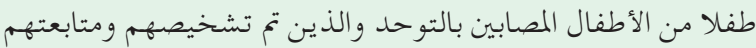

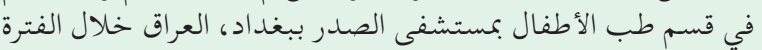

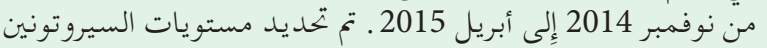

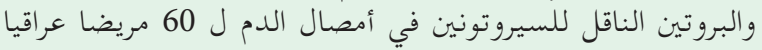

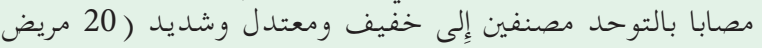

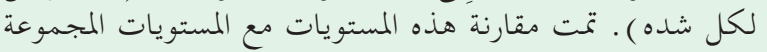
الضابطة للأطفال الأصحاء.

النتائج: لوحظ وجود زيادة ملحوظه في مستويات السيروتونين

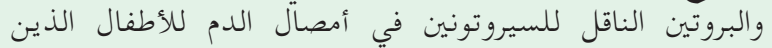

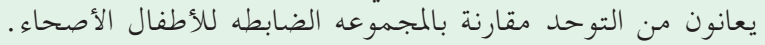

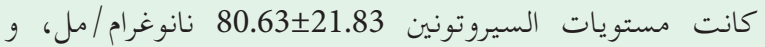

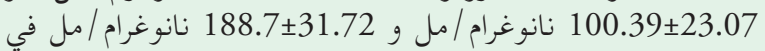

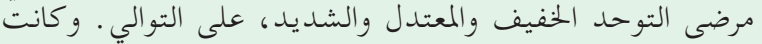
مستويات البروتين الناقل للسيروتونين SERT هي

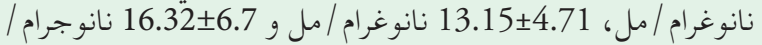

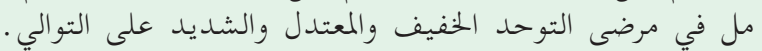

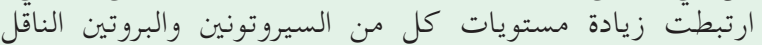

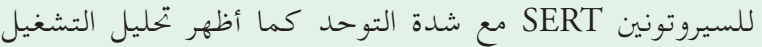

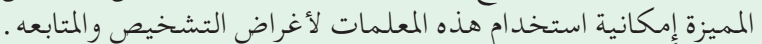

الحخاتمه : لوحظ وجود ارتفاع في مستويات السيروتونين والبروتين

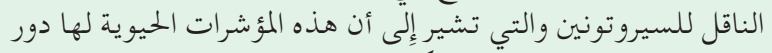

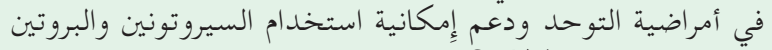

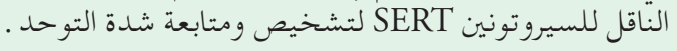

Objectives: To assess the possible correlation between serotonin and serotonin transporter (SERT) with the autism severity and investigate the association between these parameters in autistic children to assess their possible role for diagnosis of autism severity.
Methods: A comparative cross-sectional study was carried out in the Chemistry and Biochemistry Department, College of Medicine, Al-Nahrain University, Baghdad, Iraq while the samples were taken from 60 male autistic children recruited to the Department of Pediatrics at Al-Sader Hospital, Baghdad, Iraq between November 2014 amd April 2015. Levels of serotonin and serotonin transporters (SERT) were determined in 60 male autistic Iraqi patients classified into mild, moderate and severe (20 for each). These levels were compared with those of 26 healthy control children.

Results: Levels of serotonin and SERT were significantly increased in autistic children than that of gender and agematched controls. Serotonin levels were $80.63 \pm 21.83$ $\mathrm{ng} / \mathrm{ml}$ in mild, $100.39 \pm 23.07 \mathrm{ng} / \mathrm{ml}$ moderate, and $188.7 \pm 31.72 \mathrm{ng} / \mathrm{ml}$ severe autistic patients. Serotonin transporter levels were $10.13 \pm 4.51 \mathrm{ng} / \mathrm{ml}$ in mild, $13.15 \pm 4.71 \mathrm{ng} / \mathrm{ml}$ moderate, and $16.32 \pm 6.7 \mathrm{ng} / \mathrm{ml}$ in severe autistic patients. The increase of both serotonin and SERT levels were associated with severity of autism. Receiver operating characteristic (ROC) analysis can be used for diagnostic and prognostic purposes.

Conclusions: High serotonin and SERT levels may indicate that these biomarkers have a role in the autism pathogenesis and support the possibility of using serotonin and SERT to diagnose autism severity.

Saudi Med J 2018; Vol. 39 (5): 487-494 doi: $10.15537 /$ smj.2018.5.21751

From the Department of Pharmacy (Abdulamir), Al Yarmouk University College, from the Department of Chemistry and Biochemistry (Abdul-Rasheed), College of Medicine, Al-Nahrain University; and from the Mental Health (Abdulghani), Ministry of Health, Baghdad, Iraq.

Received 30th November 2017. Accepted 11th April 2018.

Address correspondence and reprint request to: Prof. Dr. Omar F. Abdul-Rasheed, Department of Chemistry and Biochemistry, College of Medicine, Al-Nahrain University, Baghdad, Iraq. E-mail:omar_rasheed39@yahoo.com

ORCID ID: orcid.org/0000-0003-3016-9176 
$A^{u}$ utism is a disorder that characterized by neurodevelopmental consequences that appear clearly throughout the first 36 months of children's life and it seems to be highly associated with neural growth changes that is occur in both pre- and postnatal periods. ${ }^{1}$ Autistic children present with various deficits including impaired social communication and interaction, stereotypical movements, or behavior in a repetitive manner, ${ }^{1,2}$ acquisition of the language besides a failure to assume a proper meaning from normal social cues and fixation on a maintained uniformity of routine. ${ }^{3}$ Additionally, autistic children also suffered from sensory abnormalities with a low threshold for sensory inputs leading to avoidance behaviors. ${ }^{3}$ Autism spectrum disorder (ASD) is generally presented as gender related disorders in which most patients are male; with a ratio of 4:1 (males to females). ${ }^{4}$ Neurotransmitters, which defined as way of connecting neurons, have crucial roles in the normal brain development, in addition to their role in the regulation of memory, behavior and motor activity. ${ }^{5}$ Thus, the dysfunction in the system of neurotransmitter may be one of autism causes that affect the migration of neuronal cell, differentiation and synaptogenesis and, finally lead to dysfunction in the processes of the brain developmental. ${ }^{6,7}$ Regarding the autism pathophysiology, several systems of neurotransmitter were investigated, and accordingly the abnormalities in these systems have shown that it may be responsible for autism. Several researches have demonstrated that the serotonergic system contains the neurotransmitters most commonly associated with autism pathogenesis. ${ }^{8}$

Many previous studies have hypothesized that there is disruption in the synaptogenesis in patients with autism, ${ }^{9}$ despite that the susceptibility to autism is related to other pathways. In this regard, many evidences either genetic or pathophysiological suggest that the different systems of neurotransmission may be involved in autism. ${ }^{10-12}$ Serotonin (5-hydroxytryptamine; 5-HT) is a neurotransmitter that belongs to monoamine family which involved in modulating cortical plasticity in adult with a significant role in early cortex development due to its role as regulator for proliferation, migration and neuronal differentiation. ${ }^{13}$ Seven families of serotonin receptors (5-HT1-5-HT7) are participating in elicit the activity of this neurotransmitter that is related mainly to

Disclosure. Authors have no conflict of interests, and the work was not supported or funded by any drug company. mood and sleep in addition to memory, learning ability, homeostasis of muscle contraction and even endocrine functions. ${ }^{14}$ The levels of serotonin either intracellularly or extracellular are regulated through the expression levels of a tissue serotonin transporter (SERT) beside its activity. ${ }^{3}$ Serotonin transporter consists of 630 amino acids with a structure similar to transporter of noradrenaline (NET) and dopamine (DAT). ${ }^{3}$ Serotonin transporter has a significant effect on the neuronal serotonin levels modulation. Several internal and external influences can affect the function and level of SERT expression significantly from the early embryonic stages through adolescence.

The SERT proteins expression affected by various protein kinase (PK)-linked pathways including signalling molecules, protein kinase C, G and p38 mitogen-activated PK (MAPK). ${ }^{3}$ Serotonin transporter levels were down-regulated by phosphorylation via protein kinase $\mathrm{C}$ pathways which is induced by the extracellular level of serotonin. ${ }^{3}$ Several physiological functions in the human body such as circadian rhythms, sleep, mood, cognition, anxiety in addition to memory formation have affected by the levels of serotonin. Low levels of serotonin may be associated with numerous features in autistic children, such as disturbances in sleep in addition to cognitive and social impairment. ${ }^{15,16}$ Several other studies have revealed that SERT and/or serotonin levels were elevated in autistic children in a comparison with controls. ${ }^{17-22}$

This study aimed to explore and test the possible role of serotonin and its transporter (SERT) in the diagnosis and prognosis of autism and to determine the correlation between these 2 markers and the disease severity.

Methods. This study was conducted as comparative cross-sectional study on 60 male autistic children selected from the Department of Pediatrics at Al-Sader Hospital, Baghdad, Iraq between November 2014 and April 2015. The age of autistic children selected was ranged between 3 and 13 years (mean \pm SD $7.28 \pm 2.89$ years) while the control group selected comprises 26 apparently healthy children with age of $6.92 \pm 2.59$ mean \pm SD years as listed in Table 1. This study was carried out at the Department of Chemistry and Biochemistry, College of Medicine, University of Al-Nahrain, Baghdad, Iraq. Sera samples from both autistic and healthy children were collected after overnight fasting. Autistic patients were defined as children who met the Diagnostic and Statistical Manual of Mental Disorders (5th ed) (DSM V) criteria for the diagnosis of autism and the International Classification of Diseases-Classification of Mental and Behavioral 
Disorders (ICD-10). The range of children's ages was from 3-13 years, and none had relatives suffers from autism.

The autistic patients were classified into mild, moderate, and severe subgroups; free from other diseases and did not receive pharmacological treatment. Control subjects were selected based on the selected autistic children. The control group included normally developing, healthy children, who did not receive any medications or meet any of the exclusion criteria, which included the following: 1) Any medical disease that is thought to cause autism such as focal epilepsy or Rett syndrome. 2) Children suffered from any neurological disorder other than uncomplicated and non-focal epilepsy that involves pathology above the brain stem. 3) Either any contemporaneous or approved retrospective evidences of possible neonatal brain damage. 4) Any central nervous system (CNS) genetic syndrome, even if the disorder that its link with autism is unclear or unapproved. 5) Significant clinical impairment in a vision or auditory capability in children even after correction. 6) Psychological deprivation, severe malnutrition or any other circumstances that may cause autism. 7) Subjects received treatment either pharmacological or even other agents like nutritional supplements and vitamins. 8) Mastocytosis (such as urticaria pigmentosa). 9) Subjects with a past history of diseases in the upper airway. 10) Children with history of allergic problems and inflammatory diseases.

The control group had no clinical indications of infectious disease or neuropsychiatric disorders.

The Institutional Review Board (IRB) and the Local Ethical Committee, College of Medicine, Al-Nahrain University, Baghdad, Iraq, approved this study. Additionally, parents or legal guardians of the investigated subjects provided an informed written consent for participation in the study in accordance with the Helsinki principles.

Sample collection. Blood samples of 5 milliliter were collected from children included to this study (both autistic and control groups) after an overnight fasting in plain tubes at $9 \mathrm{am}$. The sera were obtained and stored at $-20^{\circ} \mathrm{C}$ for the measurement of serotonin and SERT levels. Levels of serum serotonin and SERT were estimated by enzyme-linked immunosorbent assays (ELISAs) with kits obtained from the German Demeditec diagnostic $\mathrm{GmbH}$ Company with a sensitivity of $5 \mathrm{ng} / \mathrm{ml}$ and GenAsia Biotech Co., Ltd (Shanghai, China) with an excellent sensitivity of $0.5 \mathrm{ng} / \mathrm{ml}$.

Table 1 - Demographic characteristics of the autistic patients and controls.

\begin{tabular}{lcccccc}
\hline $\begin{array}{l}\text { Demographic } \\
\text { characteristics }\end{array}$ & Control & $\begin{array}{c}\text { Autistic } \\
\text { patients }\end{array}$ & $\begin{array}{c}\text { Mild } \\
\text { autism }\end{array}$ & $\begin{array}{c}\text { Moderate } \\
\text { autism }\end{array}$ & $\begin{array}{c}\text { Severe } \\
\text { autism }\end{array}$ & $P$-value \\
\hline Number & 26 & 60 & 20 & 20 & 20 \\
Age $($ year $)$ & $6.92 \pm 2.59$ & $7.28 \pm 2.89$ & $7.7 \pm 3.2$ & $6.65 \pm 2.58$ & $7.5 \pm 2.98$ & 0.31 \\
BMI $\left(\mathrm{kg} / \mathrm{m}^{2}\right)$ & $17.36 \pm 2.89$ & $16.82 \pm 3.05$ & $16.53 \pm 3.34$ & $17.2 \pm 2.91$ & $16.75 \pm 3.01$ & 0.25 \\
\hline \multicolumn{7}{c}{ BMI - body mass index } \\
\hline \multicolumn{7}{c}{}
\end{tabular}

Table 2 - Serotonin and serotonin transporter (SERT) levels in autistic and control groups.

\begin{tabular}{|c|c|c|c|c|c|c|c|c|c|}
\hline Parameters/group & $\mathrm{N}$ & Mean \pm SD & ${ }^{a} P$-value & ${ }^{\mathrm{b}} P$-value & ${ }^{c} P$-value & ${ }^{\mathrm{d}} P$-value & ${ }^{\mathrm{e}} P$-value & ${ }^{\mathrm{f}} P$-value & ${ }^{\mathrm{g}} P$-value \\
\hline Serotonin $(\mathrm{ng} / \mathrm{ml})$ & & & $<0.001$ & 0.581 & 0.017 & $<0.001$ & 0.64 & $<0.001$ & $<0.001$ \\
\hline Control & 26 & $54.97 \pm 18.43$ & & & & & & & \\
\hline Autistic patients & 60 & $123.24 \pm 28.49$ & & & & & & & \\
\hline Mild & 20 & $80.63 \pm 21.83$ & & & & & & & \\
\hline Moderate & 20 & $100.39 \pm 23.07$ & & & & & & & \\
\hline Severe & 20 & $188.7 \pm 31.72$ & & & & & & & \\
\hline $\operatorname{SERT}(\mathrm{ng} / \mathrm{ml})$ & & & 0.031 & 0.91 & 0.043 & $<0.001$ & 0.039 & 0.087 & $<0.001$ \\
\hline Control & 26 & $10.53 \pm 2.95$ & & & & & & & \\
\hline Autistic patients & 60 & $13.2 \pm 5.88$ & & & & & & & \\
\hline Mild & 20 & $10.13 \pm 4.51$ & & & & & & & \\
\hline Moderate & 20 & $13.15 \pm 4.71$ & & & & & & & \\
\hline Severe & 20 & $16.32 \pm 6.7$ & & & & & & & \\
\hline $\begin{array}{l}{ }^{a} P \text {-value between a } \\
{ }^{c} P \text {-value between n } \\
\text { (Tukey test), }{ }^{\mathrm{e}} P \text {-v }\end{array}$ & $\begin{array}{l}\text { pati } \\
\text { tely } \\
\text { twee } \\
\text { au }\end{array}$ & $\begin{array}{l}s \text { and controls ( } \\
\text { tistic patients an } \\
\text { mildly and mod } \\
\text { tic patients (Tuk }\end{array}$ & $\begin{array}{l}\text { zey test). }{ }^{\mathrm{b}} \\
\text { ontrols ( } \mathrm{T} \\
\text { tely autisti } \\
\text { test), }{ }^{\mathrm{g}} P \text {-v }\end{array}$ & $\begin{array}{l}P \text {-value bet } \\
\text { ukey test), } \\
\text { c patients } \\
\text { llue betwe }\end{array}$ & $\begin{array}{l}\text { ween mildl } \\
P \text {-value be } \\
\text { Tukey test) } \\
n \text { all group }\end{array}$ & $\begin{array}{l}\text { autistic pa } \\
\text { ween sever } \\
{ }^{\mathrm{f}} P \text {-value b }\end{array}$ & $\begin{array}{l}\text { tients and } \\
\text { ely autistic } \\
\text { tween mo } \\
\text { test) }\end{array}$ & $\begin{array}{l}\text { controls (1 } \\
\text { patients ar } \\
\text { lerately an }\end{array}$ & $\begin{array}{l}\text { key test), } \\
\text { controls } \\
\text { severely }\end{array}$ \\
\hline
\end{tabular}


Statistical analysis. The results obtained in this study were expressed as mean $\pm S D$, and statistical comparisons were conducted with the use of independent t-test for comparing 2 independent groups (patients and controls). Analysis of variance (ANOVA) test for a comparison among more than 2 groups using Tukey HSD post-Hoc test to assess the significant differences between studied subgroups; considered $p<0.05$ as statistically significant. Correlations among all studied parameters were tested by the Pearson correlation test, and all statistical analyses used in this study were carried out by using the IBM SPSS Statistics for Windows, Version 20.0 (Armonk, NY: IBM Corp). The normality of distribution was checked using Shapiro- Wilk and Kolmogorov-Smirnov tests.

Receiver operating characteristic (ROC) analyses were accomplished as comprehensive way to determine the accuracy of the markers used in this study. In ROC analysis, area under the curve (AUC) can be considered as a powerful statistical tool for comparing different biomarkers given the value of AUC that become closer to one indicates that the parameter can be considered as an excellent diagnostic and predictive biomarkers, a curve obtained in this statistical analysis may indicate the significance of the marker. So, the curve of a parameter that lies close to the diagonal $(A U C=0.5)$ indicate no diagnostic significance. An AUC value that is closer to one is always coupled with sensitivity and specificity satisfactory values. ${ }^{24}$

Results. The serotonin and SERT levels were compared between patients with varying levels of autism severity (mild, moderate, severe) and age-matched control subjects. Table 2 shows that the levels of serotonin and SERT in autistic patients were elevated compared with those of the controls $(p<0.001$ and $p=0.031)$. Serotonin levels were non-significantly $(p=0.581)$ different between mildly autistic patients and controls, whereas significant differences were found between moderately $(p=0.017)$ and severely autistic patients relative to the controls. In contrast, a non-significant $(p=0.64)$ difference was found between moderately and mildly autistic patients, and a significant $(p<0.001)$ increase in serotonin levels was noted in severely autistic patients relative to moderately autistic patients SERT levels were non-significantly $(p=0.91)$ different between mildly autistic patients and controls, whereas significant differences were found between moderately $(p=0.043)$ and severely $(p<0.001)$ autistic patients compared with controls. A significant $(p=0.039)$ difference was also found between moderately and mildly autistic patients, and a non-significant difference $(p=0.087)$ was noted
Table 3 - Correlations of the serotonin and serotonin transporter (SERT) levels among the different study groups.

\begin{tabular}{lccc}
\hline Group & N & $\begin{array}{c}\text { r } \\
\text { (Pearson } \\
\text { correlation } \\
\text { coefficient) }\end{array}$ & Significance \\
\hline Control & 26 & 0.174 & 0.437 \\
Autistic patients & 60 & 0.46 & $<0.001$ \\
Mildly autistic patients & 20 & 0.075 & 0.752 \\
Moderately autistic patients & 20 & -0.288 & 0.218 \\
Severely autistic patients & 20 & 0.721 & $<0.001$ \\
\hline
\end{tabular}

between severely and moderately autistic patients. According to ANOVA, the serotonin and serotonin transporter levels were significantly different across all studied groups $(p<0.001, \mathrm{f}=9.81$ and $\mathrm{p}<0.001, \mathrm{f}=7.48$, respectively).

Table 3 shows a positive and significant correlation between serotonin and SERT levels among all autistic patients $(\mathrm{r}=0.46 ; p<0.001)$ and in severely autistic patients $(\mathrm{r}=0.721 ; p<0.001)$. In contrast, non-significant correlations were found between serotonin and SERT levels in control subjects and mildly and moderately autistic patients.

Table 4 lists the ROC analysis data (the AUC, cut-off values, specificity, and sensitivity) of the measured parameters. Serotonin exhibited AUC values exceeding 0.7 among all autistic patients $(A U C=0.75)$ and in moderately $(\mathrm{AUC}=0.73)$ and severely autistic patients $(\mathrm{AUC}=0.9)$ with satisfactory values of accuracy presented as good specificity and sensitivity.

The serotonin transporter levels had AUC values higher than 0.7 in moderately $(\mathrm{AUC}=0.71)$ and severely autistic patients $(\mathrm{AUC}=0.8$ ) with satisfactory values of accuracy presented as good specificity and sensitivity.

Figures $1 \& 2$ present the ROC curves for serotonin and SERT among all the autistic children and for severely autistic children.

Discussion. Several previous studies have demonstrated that serotonergic systems may provide a promising and represent good candidates for the determination of the susceptibility to autism. ${ }^{16}$ Many previous association studies have been accomplished, but the results obtained were controversial. ${ }^{16-18,22}$ In the present study, the levels of both serotonin and its transporter were measured and compared with age- and gender-matched control subjects, and a significant increase in the levels of serotonin and SERT was observed in autistic patients. The results of this study were in consistent with those obtained from previous researches that demonstrate a significant elevation in the levels of 
Table 4 - The ROC curves of the serotonin and serotonin transporter (SERT) levels in all of the studied groups.

\begin{tabular}{|c|c|c|c|c|c|}
\hline Parameters/group & $\mathrm{N}$ & AUC & $\begin{array}{l}\text { Best cut-off } \\
\text { value }\end{array}$ & $\begin{array}{c}\text { Sensitivity } \\
\%\end{array}$ & $\begin{array}{c}\text { Specificity } \\
\%\end{array}$ \\
\hline \multicolumn{6}{|l|}{ Serotonin $(\mathrm{ng} / \mathrm{ml})$} \\
\hline Autistic patients & 60 & 0.75 & 58.82 & 75 & 65.4 \\
\hline Mildly autistic patients & 20 & 0.62 & 55.82 & 60 & 61.5 \\
\hline $\begin{array}{l}\text { Moderately autistic } \\
\text { patients }\end{array}$ & 20 & 0.73 & 61.98 & 70 & 65.4 \\
\hline Severely autistic patients & 20 & 0.90 & 84.13 & 85 & 73.1 \\
\hline \multicolumn{6}{|l|}{$\operatorname{SERT}(n g / m l)$} \\
\hline Autistic patients & 60 & 0.65 & 11.32 & 65 & 61.5 \\
\hline Mildly autistic patients & 20 & 0.52 & 11.36 & 55 & 61.5 \\
\hline $\begin{array}{l}\text { Moderately autistic } \\
\text { patients }\end{array}$ & 20 & 0.71 & 12.28 & 65 & 76.9 \\
\hline Severely autistic patients & 20 & 0.80 & 13.01 & 65 & 84.6 \\
\hline \multicolumn{6}{|c|}{ AUC - area under the curve } \\
\hline
\end{tabular}

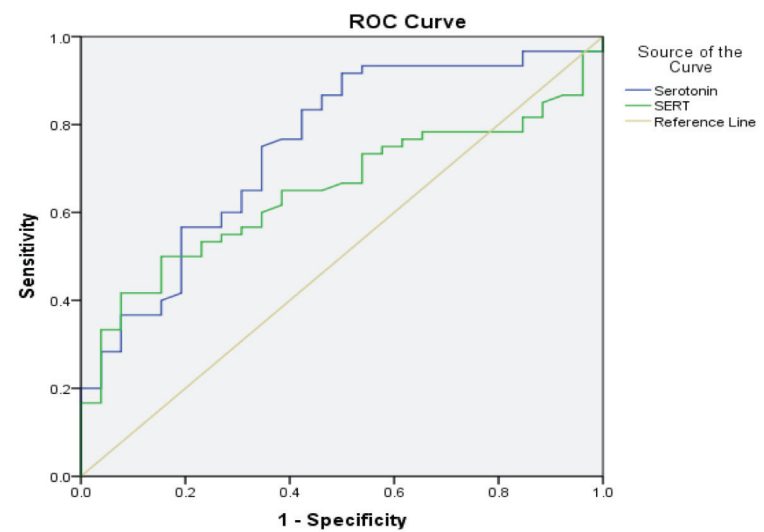

Figure 1 - Receiver operating characteristic curve of the serotonin and serotonin transporter (SERT) levels in autistic children.

serum serotonin in autistic children in a comparison with control subjects and assumed that serotonin may have an important role in the autistic symptoms. ${ }^{2,17}$ In studies conducted previously, hyperserotonemia was consistently reported in $22-29 \%$ of patients suffering from ASD that makes serotonin considered as the bestcharacterized autistic biomarker. ${ }^{16}$ Hyperserotonemia in autistic patients are seemingly owned to the excessive accumulation of serotonin within the platelets, whereas the level of free serotonin were not affected. ${ }^{17,18}$ The uptake of 5-HT into platelets is mediated by serotonin transporter similar to that expressed in neurons. ${ }^{19}$ Several studies have reported that density of SERT on the platelet membrane (Vmax) have increased in autistic patients, whereas the affinity of SERT $(\mathrm{Kd})$ for serotonin remain unchanged. ${ }^{19-21}$ In contrast, some studies have reported that the levels of serotonin in platelet-free plasma were significantly decreased in

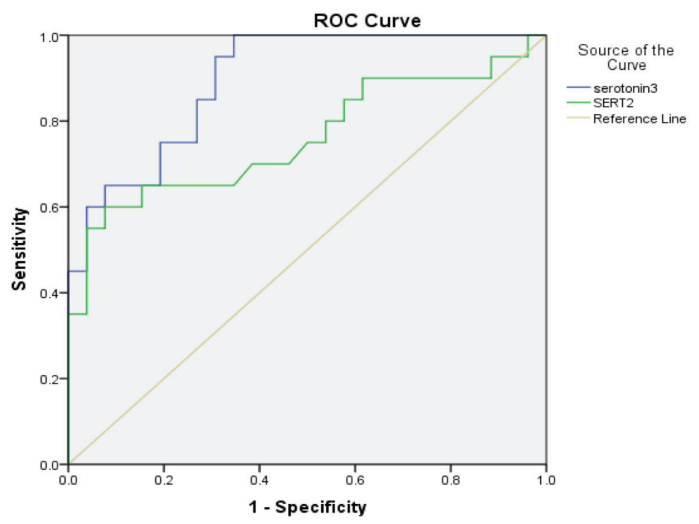

Figure 2 - Receiver operating characteristic curve of the serotonin and serotonin transporter (SERT) levels in severely autistic children.

autistic patients when compared to control subjects. ${ }^{19}$ These findings do not necessarily disagree with the hyperserotonemia demonstrated in the current study or the results obtained from the assessment of serotonin levels in samples of whole blood or platelet-rich plasma of autistic patients. ${ }^{22}$ Given that about $99 \%$ of serotonin in the circulation is confined in platelets owning to the role of SERTs, ${ }^{19}$ the results of hyperserotonemia that obtained previously in whole blood ${ }^{25}$ or platelet-rich plasma $^{26}$ of autistic patients in addition to the low levels of serotonin in platelet-free plasma ${ }^{26,27}$ reported in other studies could be resulted from i) increase in the production of serotonin, ii) increase of expression of the transporter protein on the surface of platelets, or both. ${ }^{15-22}$ The lack of a biochemical association between low levels of serotonin in platelet-free plasma and the severity of autism assumed that plateletrelated hyperserotonemia has an important role in the 
pathogenicity of this disorder. ${ }^{22,26-28}$ Additionally, recent studies conduct on a serum serotonin in autistic patients showed an increase in the level of serum serotonin in comparison with control which are in agreement with results obtained in this study. ${ }^{28,29}$ The levels of serotonin in autistic children examined in the current study were non-significantly increased in mildly autistic patients, significantly increased in moderately autistic patients and significantly increased in severely autistic patients compared with the controls. The levels of serotonin were non-significantly increased in moderately autistic patients compared with mildly autistic patients, whereas they were significantly increased in severely autistic patients in a comparison with moderately autistic patients.

These results indicate that the levels of serotonin are correlated with autism severity. These findings support the possible involvement of serotonin in autism pathogenesis and its crucial role in the diagnosis of autism and the assessment of autism severity for prognostic purposes. The results of this study were in agreement with those of other studies demonstrating a correlation between hyperserotonemia and autism severeity ${ }^{30}$ and with previous work by Hranilovic et $\mathrm{al}^{31}$ reporting a significant negative relationship between peripheral serotonin concentrations and verbal abilities in autistic subjects.

The hyperserotonemia reported in this and previous studies in autistic serum, whole blood or platelet-rich plasma ${ }^{17,25,26}$ and the low serotonin levels recorded in platelet-free plasma previously ${ }^{22,27}$ could be the result of increased serotonin production in the intestine, ${ }^{32}$ increased expression and density of the transporters on platelet surfaces, ${ }^{21,22}$ altered release from enterochromaffin cells, ${ }^{31}$ or diminished release from platelets. ${ }^{31}$ However, the mechanism underlying the observed phenomenon and its relationship to central 5-HT dysfunction remain unclear. ${ }^{16}$ Serotonin transporter was the second parameter measured in this study and was selected because of its important role in serotonergic transmission. ${ }^{3}$ In the brain, SERT clears serotonin from extracellular spaces, modulating the strength and duration of serotonergic signalling. ${ }^{15}$ Outside the CNS, it is also present in platelets, where it takes up serotonin from plasma at very low levels. ${ }^{33}$ Importantly, it is generally accepted that the serotonin transporter proteins expressed in platelets are identical to those found in neurons, displaying similar structural and functional properties in both tissues. ${ }^{33}$ In the present study, the levels of SERT in autistic patients were significantly higher than in controls. The levels of serum SERT represent the amount of SERT released from platelets. Consistent with the results obtained here, many other studies have demonstrated that SERT levels are elevated in autistic patients. ${ }^{19,21,22,34}$ Increased SERT levels may result from the reduced SERTbinding capacity reported in children with ASD. ${ }^{34}$ The expected defect in the binding capacity of SERT may indicate that serotonin levels are low in the brain despite hyperserotonemia because serotonin cannot cross the blood-brain barrier. ${ }^{35}$ Elevated serotonin levels in autism might also be related to defects in serotonin receptors ${ }^{17,36}$ resulting from an autoimmune reaction in the brain, ${ }^{37}$ which may explain the high serotonin levels observed in autistic patients and the subsequent elevated SERT levels. Thus, further immunological studies to identify the exact cause of high serotonin and SERT levels in autistic patients are needed.

In contrast, other studies have found that some mutations in the SERT gene cause a gain-of-function leading to increased SERT expression. ${ }^{38}$ Serotonin transporter is responsible for the termination of serotonin action within the brain, ${ }^{19}$ and thus, increased expression of the SERT gene may reduce the effect of serotonin inside the brain. The results obtained in this study may be consistent with this explanation because the levels of both serotonin and SERT were elevated, and the elevations corresponded to the severity of autism, as shown in Table 2.

Interestingly, a significant positive correlation between serotonin and SERT in autistic patients and a significant positive correlation in severely autistic patients were noted, whereas the serotonin and SERT levels of mildly and moderately autistic patients were non-significantly correlated. Possible explanations for this positive correlation between serotonin and SERT are as follows: 1) the defect in the binding capacity of SERT reduces the amount of serotonin released in the brain, thereby inducing serotonin synthesis to compensate for the reduced levels of serotonin in the brain ${ }^{35}$ and possibly causing an increase in the SERT level; 2) the defect in the serotonin receptor causes an elevation in the serotonin level to reverse the abnormal serotonergic transmission, ${ }^{36,37}$ which may be accompanied with an increase in SERT level; or 3) the mutation in the SERT gene increases SERT expression by affecting the pattern of regulation ${ }^{38}$ and, as a result, increases the serotonin level. ${ }^{39}$ These possible explanations may be clearer and more pronounced in severely autistic patients, although they are also present in mildly and moderately autistic patients. The ROC curve analysis reveals that the serum serotonin test is an adequate diagnostic and predictive marker with acceptable sensitivity and specificity in autistic patients, whereas SERT is a relatively poor 
diagnostic marker in autistic patients, especially in mildly autistic children in which the AUC was close to 0.5. The serotonin and SERT tests revealed increased AUC values as autism became more severe. The results revealed that serotonin test can be considered as an excellent diagnostic and predictive marker in severely autistic patients, whereas SERT considered as a good diagnostic and predictive marker in severely autistic patients.

One major limitation of this comparative crosssectional study was the small number of children examined, which may affect the statistical power and the precision of the estimated sensitivity and specificity of serotonin and serotonin transporter levels. The sample size in this research depends primarily on the number of patients that have the inclusion criteria and referred the hospital during the period of study taking in the consideration that autism is a rare disease in Iraq. Furthermore, we evaluated only a single hospital. Further work is needed on a larger scale involving different areas of Iraq to address these limitations and platelets count should be assessed as a confounding factor. This study can be considered as one of the first studies on the level of serotonin and its transporter in serum samples of Iraqi children with autism. Further studies involve the estimation of the levels of serotonin metabolites to improve the outcome of the study.

In conclusion, results obtained in the current study revealed that the levels of serotonin and its transporter were significantly elevated in autistic children in a comparison with that of controls, and this increase correlates with the severity of autism.

Furthermore, this study demonstrated that there was a significant positive correlation between these two parameters, and ROC curve results obtained may indicate the possibility of using these two parameters as diagnostic and prognostic markers and for the assessment of autism severity.

Acknowledgment. The authors are grateful to the staff of the Department of Chemistry and Biochemistry, College of Medicine Al-Nahrain University, for their assistance in performing this study. Dr. Basim D. Sadiq, Ibn-Rushd Psychiatric Teaching Hospital, Baghdad, Iraq, the head and staff members of the Pediatric Department at Al-Sader Hospital, and the head and staff members of the laboratories at Al-Sader Hospital are also acknowledged.

\section{References}

1. Abdulamir HA, Abdul-Rasheed OF, Abdulghani EA. Low oxytocin and melatonin levels and their possible role in the diagnosis and prognosis in Iraqi autistic children. Saudi Med J 2016; 37: 29-36.
2. Zafeiriou D, Ververi A, Vargiami E. The serotonergic system: its role in pathogenesis and early developmental treatment of autism. Curr Neuropharmacol 2009; 7: 150-157.

3. Rose'Meyer R. A review of the serotonin transporter and prenatal cortisol in the development of autism spectrum disorders. Mol Autism 2013; 4: 37.

4. Halladay AK, Bishop S, Constantino JN, Daniels AM, Koenig $\mathrm{K}$, Palmer $\mathrm{K}$, et al. Sex and gender differences in autism spectrum disorder: summarizing evidence gaps and identifying emerging areas of priority. Mol Autism 2015; 6: 36.

5. Quaak I, Brouns MR, Van de Bor M. The dynamics of autism spectrum disorders: how neurotoxic compounds and neurotransmitters interact. Int J Environ Res Public Health 2013; 10: 3384-3408.

6. Arya A, Sindhwani G. Autism. An early-onset neurodevelopmental disorder. International Journal of Pharmaceutical Sciences and Research 2016; 7: 3567-3575.

7. Carla AM, Herrington J, Siegel M, Scarpa A, Brenna BM, Scahill $\mathrm{L}$ and Susan WW. The role of emotion regulation in autism spectrum disorder. J Am Acad Child Adolesc Psychiatry 2013; 52: 679-688.

8. Celada P, Puig MV, Artigas F. Serotonin modulation of cortical neurons and networks. Front Integr Neurosci 2013; 7: 25.

9. Adamsen D, Ramaekers V, Ho HTB, Britschgi C, Rüfenacht V, Meili D, et al. Autism spectrum disorder associated with low serotonin in CSF and mutations in the SLC29A4 plasma membrane monoamine transporter (PMAT) gene. Molecular Autism 2014; 43: 2-11.

10. Ecker C, Bookheimer SY, Murphy DG. Neuroimaging in autism spectrum disorder: brain structure and function across the lifespan. Lancet Neurol 2015; 14: 1121-1134.

11. Berg AT, Dobyns WB. Progress in autism and related disorders of brain development. Lancet Neurol 2015; 14: 1069-1070.

12. Hamilton PJ, Campbell NG, Sharma S. De novo mutation in the dopamine transporter gene associates dopamine dysfunction with autism spectrum disorder. Mol Psychiatry 2013; 18: 1315-1323.

13. Jenkins TA, Nguyen JC, Polglaze KE, Bertrand PP. Influence of tryptophan and serotonin on mood and cognition with a possible role of the gut-brain axis. Nutrients 2016; 8: pii: E56.

14. Meyer RR. A review of the serotonin transporter and prenatal cortisol in the development of autism spectrum disorders. Molecular Autism 2013; 37: 2-16.

15. Meneses A. 5-HT systems: emergent targets for memory formation and memory alterations. Rev Neurosci 2013; 24: 629-664.

16. Gabriele S, Sacco R, Persico AM. Blood serotonin levels in autism spectrum disorder: a systematic review and metaanalysis. Eur Neuropsychopharmacol 2014; 24: 919-929.

17. Muller CL, Anacker AMJ, Veenstra-VanderWeele J. The serotonin system in autism spectrum disorder: From biomarker to animal models. Neuroscience 2016; 321: 24-41.

18. Ruggeri B, Sarkans U, Schumann G, Persico AM. Biomarkers in autism spectrum disorder: the old and the new. Psychopharmacology 2014; 231: 1201-1216.

19. Meguid NA, Gebril OH, Khalil RO. A study of blood serotonin and serotonin transporter promoter variant (5-HTTLPR) polymorphism in Egyptian autistic children. Adv Biomed Res 2015; 4: 94.

20. Siemann JK, Muller CL, Forsberg CG, Veenstra-VanderWeele J, Wallace MT. An autism-associated serotonin transporter variant disrupts multisensory processing. Transl Psychiatry 2017; 7: e1067. 
21. Yang CJ, Tan HP, Du YJ. The developmental disruptions of serotonin signaling may be involved in autism during early brain development. Neuroscience 2014; 267: 1-10.

22. Alabdali A, Al-Ayadhi L, El-Ansary A. Association of social and cognitive impairment and biomarkers in autism spectrum disorders. J Neuroinflammation 2014; 11: 4.

23. American Psychiatric Association. Diagnostic and statistical manual of mental disorders. 5th ed. Washington (DC): American Psychiatric Association; 2013.

24. Hajian-Tilaki K. Receiver operating characteristic (ROC) curve analysis for medical diagnostic test evaluation. Caspian J Intern Med 2013; 4: 627-635.

25. Veenstra-VanderWeele J, Muller CL, Iwamoto H, Sauer JE, Owens WA, Shah CR, et al. Autism gene variant causes hyperserotonemia, serotonin receptor hypersensitivity, social impairment and repetitive behavior. Proc Natl Acad Sci USA 2012; 109: 5469-5474.

26. Bijl N, Thys C, Wittevrongel C, De la Marche W, Devriendt $\mathrm{K}$, Peeters $\mathrm{H}$, et al. Platelet studies in autism spectrum disorder patients and first-degree relatives. Mol Autism 2015; 6: 57.

27. Anderson GM, Cook EH Jr. Commentary on "Platelet Studies in Autism Spectrum Disorder Patients and First-Degree Relatives". Mol Autism 2016; 7: 20.

28. Dayem H, Bordeny M, Ragheb D. Study of serum level of serotonin in children with autism spectrum disorder. $E C$ Paediatrics 2018; 7: 11-18.

29. Yang CJ, Liu CL, Sang B, Zhu XM, Du YJ. The combined role of serotonin and interleukin- 6 as biomarker for autism. Neuroscience 2015; 284: 290-296.

30. Tordjman S, Anderson GM, Cohen D, Kermarrec S, Carlier M, Touitou Y, et al. Presence of autism, hyperserotonemia, and severe expressive language impairment in Williams-Beuren syndrome. Mol Autism 2013; 4: 29.
31. Hranilovic D, Bujas-Petkovic Z, Vragovic R, Vuk T, Hock K, Jernej B. Hyperserotonemia in adults with autistic disorder. $J$ Autism Dev Disord 2007; 37: 1934-1940.

32. Hsiao EY. Gastrointestinal issues in autism spectrum disorder. Harv Rev Psychiatry 2014; 22: 104-111.

33. Yubero-Lahoz S, Robledo P, Farré M, de la Torre R. Platelet SERT as a peripheral biomarker of serotonergic neurotransmission in the central nervous system. Curr Med Chem 2013; 20: 1382-1396.

34. Iwata K, Matsuzaki H, Tachibana T, Ohno K, Yoshimura S, Takamura $\mathrm{H}$, et al. N-ethylmaleimide-sensitive factor interacts with the serotonin transporter and modulates its trafficking: implications for pathophysiology in autism. Mol Autism 2014; 5: 33 .

35. Janušonis S. Serotonin dynamics in and around the central nervous system: Is autism solvable without fundamental insights? Int J Dev Neurosci 2014; 39: 9-15.

36. Prafullata S.Bhakare PS, Vinchurkar A. Study of serotonin level in autism. Indian Journal of Basic and Applied Medical Research 2016: 5: 550-553

37. Gottfried C, Bambini-Junior V, Francis F, Riesgo R, Savino W. The Impact of Neuroimmune Alterations in Autism Spectrum Disorder. Front Psychiatry 2015; 6: 121.

38. Margolis KG, Li Z, Stevanovic K, Saurman V, Israelyan N, Anderson GM, et al. Serotonin transporter variant drives preventable gastrointestinal abnormalities in development and function. J Clin Invest 2016; 126: 2221-2235.

39. Veenstra-VanderWeele J, et al. Autism gene variant causes hyperserotonemia, serotonin receptor hypersensitivity, social impairment and repetitive behavior. Proc Natl Acad Sci US A 2012; 109: 5469-5474. 